\title{
HUBUNGAN PELAKSANAAN PROGRAM KESELAMATAN DAN KESEHATAN KERJA DENGAN PRODUKTIVITAS KERJA PADA BURUH PROYEK MAKASSAR NEW PORT DI PT. PP (PERSERO) TBK
}

The Relationship between Occupational Safety and Health Program Implementation and Work Productivity in Makassar New Port Project Workers at PT. PP (Persero) Tbk

La Taha, Diah Ayu Lestari

Jurusan Kesehatan Lingkungan Poltekkes Kemenkes Makassar lataha1962@gmail.com

\begin{abstract}
Human resources need to be protected, through the implementation of occupational safety and health programs that must be carried out consistently. Occupational safety and health programs are closely related to the work productivity of a workforce, thus if the implementation of occupational safety and health programs is carried out properly it will increase labor productivity. This research is an analytical observational study with a cross-sectional research design, to determine the relationship between occupational safety and health programs and work productivity. The number of samples was 153 with the sampling method using random sampling and data analysis carried out statistical tests. The results showed that of the four variables studied, 2 variables did not have a significant relationship, namely K3 counseling with a p-value of 0.159 and K3 training with a p-value of 0.954 while for the periodic health check variable with a p-value of 0.002 and the use of PPE with a value of $p=0.023$ has a significant relationship with the work productivity of a worker.It can be concluded from the results of this study that the K3 counseling and $K 3$ training variables have no relationship with work productivity, while for the variables of periodic health checks and the use of PPE there is a relationship with the work productivity of a worker. It is hoped that workers at PT. PP (Persero) Tbk, when working to reduce the risk of decreasing work productivity so that workers can increase discipline in the use of PPE during work and carry out regular health checks at least once a year.
\end{abstract}

Keywords: Work Productivity, Labor, OSH Counseling, OSH Training, Use of PPE

\section{ABSTRAK}

Sumber daya manusia perlu dilindungi, dengan program pelaksanaan keselamatan dan kesehatan kerja harus dilakukan konsisten. Program keselamatan dan kesehatan kerja erat kaitannya dengan produktivitas kerja seorang tenaga kerja, demikian jika pelaksanaan program keselamatan dan kesehatan kerja terlaksana dengan baik akan meningkatkan produktivitas tenaga kerja. Penelitian ini merupakan penelitian observasional analitik dengan rancangan penelitian secara cross sectional, untuk mengetahui hubungan program keselamatan dan kesehatan kerja dengan produktivitas kerja. Jumlah sampel 153 dengan metode pengambilan sampel menggunakan random sampling dan analisis data melakukan uji statistik. Hasil penelitian menunjukkan bahwa dari empat variabel yang diteliti terdapat dua variabel yang tidak memiliki hubungan yang signifikan yaitu penyuluhan K3 dengan nilai $(p=0,159)$ dan pelatihan K3 dengan nilai $(p=0,954)$ sedangkan untuk variabel pemeriksaan kesehatan berkala dengan nilai $(p=0,002)$ dan penggunaan APD dengan nilai $(p=0,023)$ memiliki hubungan yang signifikan dengan produktivitas kerja seorang buruh. Dapat disimpulkan hasil penelitian ini variabel penyuluhan K3 dan pelatihan K3 tidak ada hubungan dengan produktivitas kerja sedangkan untuk variabel pemeriksaan kesehatan berkala dan penggunaan APD ada hubungan dengan produktivitas kerja seorang buruh. Diharapkan kepada buruh di PT. PP (Persero) Tbk, ketika bekerja untuk meminimalisir risiko menurunnya produktivitas kerja agar para buruh dapat meningkatkan kedisiplinan dalam penggunaan APD selama bekerja dan melakukan pemeriksana kesehatan berkala minimal satu tahun sekali.

Kata Kunci: Buruh, Pelatihan K3, Penggunaan APD, Penyuluhan K3, Produktivitas Kerja

\section{PENDAHULUAN}

Sumber daya manusia perlu dilindungi, melalui program pelaksanaan kesehatan dan keselamatan kerja harus dilakukan secara konsisten. Hal ini sesuai dengan Peraturan Pemerintah No. 88 Tahun 2019 tentang Kesehatan Kerja, Pasal 1 ayat 1 "Kesehatan kerja adalah upaya yang ditujukan untuk melindungi setiap orang yang berrada di Tempat Kerja agar hidup sehat dan terbebas dari gangguan kesehatan serta pengaruh buruk yang diakibatkan dari pekerjaan". Dan Pasal 2 ayat 2 "Upaya peningkatan kesehatan dilaksanakan untuk memperoleh derajat kesehatan setinggi-tingginya pada kondisi sehat, bugar, dan produktif".

PT Pelabuhan Indonesia IV (Persero) berupaya memanfaatkan peluang dalam rangka peningkatan kinerja korporasi. Salah satunya adalah eksekusi pembangunan Makassar New Port sebagai gerbang utama percepatan pembangunan Kawasan Timur Indonesia khususnya wilayah Makassar. PT
Pelabuhan Indonesi IV menargetkan Makassar New Port (MNP) dapat mengakomodir tingkat arus peti kemas dalam jangka panjang hingga tahun 2025.

Pertumbuhan ekonomi di Kota Makassar pada khususnya maupun Indonesia Timur pada umumnya akan memicu peningkatan arus peti kemas maupun barang untuk memenuhi kebutuhan permintaan yang terus meningkat seiring dengan pertumbuhan penduduk (Kadir, A. $R, 2018)$.

Pada observasi awal yang dilakukan peneliti pada buruh di PT. PP (Persero) Tbk, tingkat kedisiplinan tenaga kerja dalam menggunakan APD masih tergolong rendah dikarenakan jika berada di area konstruksi pembangunan tidak menggunakan helm dan kemudian beberapa tenaga kerja tidak menggunakan sepatu boots sesuai standar. Kegiatan penyuluhan dan pelatihan K3 amat sangat penting peranannya bagi tenaga kerja untuk meningkatkan pengetahuan keselamatan kerja dan pencegahan 
Jurnal Sulolipu : Media Komunikasi Sivitas Akademika dan Masyarakat

Vol. 21 No.2 2021

e-issn : 2622-6960, p-issn : 0854-624X

kecelakaan. Kemudian pemeriksaan kesehatan yang rutin dilakukan setiap 6 bulan sekali oleh pihak perusahaan dan tiap 1 tahun sekali dilakukan pelatihan keselamatan dan kesehatan kerja serta penyuluhan oleh tim audit K3 perusahaan.

Berdasarkan kemungkinan adanya penyimpangan dalam pelaksanaan Program Keselamatan dan Kesehatan Kerja pada Proyek Makassar New Port di PT. PP (Persero) Tbk maka peneliti tertarik mengkaji lebih dalam mengenai pelaksanaan Program Keselamatan dan Kesehatan Kerja agar tercipta Produktivitas Kerja yang efektif di perusahaan.

\section{METODE}

Penelitian ini dilakukan pada Proyek Makassar New Port di PT. PP (Persero) Tbk. Jenis penelitian ini termasuk dalam observasional analitik menggunakan desain penelitian cross sectional. Populasi dari penelitian ini seluruh buruh kerja pada Proyek Makassar New Port di PT. PP (Persero) Tbk yaitu 250 orang. Subyek penelitian ini sebanyak 153 orang yang dihitung rumus slovin. Teknik pengambilan sampel yaitu random sampling.

\section{TEKNIK PENGUMPULAN DATA}

\section{Data Primer}

Data primer adalah sumber data penelitian dari PT. PP (Persero) Tbk diperoleh secara langsung dari sumber aslinya yang berupa observasi dan wawancara kepada buruh kerja Proyek Makassar New Port.

2. Data Sekunder

Data sekunder adalah sumber data penelitian dari PT. PP (Persero) Tbk melalui media prantara atau secara tidak langsung yang merupakan buku, catatan, dan hasil penelitian lainnya yang berhubungan dengan objek penelitian.

\section{PENGOLAHAN DAN ANALISIS DATA}

Data diolah menggunakan program computer, melalui proses editing, coding, data entry, dan tabulasi yang selanjutnya dianalisis menggunakan analisis univariate dan bivariate dengan melakukan uji pearson shi square.

HASIL

Kegiatan penelitian dilaksanakan sejak April-Mei 2021 bertempat di proyek Makassar New Port PT. PP (Persero) Tbk. Pengambilan data melalui kuesioner dan observasi langsung yang dilakukan terhadap buruh proyek MNP berdasarkan pengolahan data maka data maka dapat dilihat pembahasan berikut:

\section{PEMBAHASAN}

\section{Hubungan Penyuluhan K3 dengan Produktivitas Kerja}

Berdasarkan hasil penelitian yang telah dilakukan diperoleh hasil uji Chi Square sebesar $p=0,159>\alpha=0,05$ yang dapat diartikan bahwa $\mathrm{HO}$ diterima dan $\mathrm{Ha}$ ditolak karena tidak terdapat hubungan antara penyuluhan K3 dengan produktivitas kerja.

Hal ini sejalan dengan penelitian yang dilakukan oleh Dwi Purwati (2018) yang menyatakan tidak ada hubungan antara penyuluhan K3. Bahwa setiap kegiatan penyuluhan tentang keselamatan dan kesehatan kerja yang dilaksanakan oleh PT. PP (Persero) Tbk tidak mengalami peningkatan produktivitas kerja buruh dengan nilai yang diperoleh sebesar 0,159. Aspek mutlak yang diperlukan dalam rangka peningkatan suatu produktivitas kerja buruh dilihat dari pola pikir dan perilaku yang baik sehinga dapat digunakan serta menerapkan di dalam pekerjaannya.

Pada dasarnya tenaga kerja dalam hal ini buruh seharusnya memperhatikan keselamatan terutama pada dirinya sendiri. Maka dari itu dalam bekerja hendaknya selalu memperhatikan rambu-rambu keselamatan dan mengikuti penyuluhan agar pekerja tetap waspada terhadap potensi bahaya yang mungkin tidak terlihat sehingga tidak membayakan diri sendiri.

\section{Hubungan Pelatihan K3 dengan Produktivitas Kerja}

Berdasarkan tabel 5.10 hasil penelitian yang telah dilakukan di PT. PP (Persero) Tbk Proyek Makassar New Port hasil uji Chi Square menunjukkan $p=0,954>\alpha=0,05$ dengan demikian $\mathrm{HO}$ diterima dan Ha ditolak tidak ditemukan hasil yang signifikan adanya hubungan antara pelatihan K3 dengan produktivitas kerja.

Hasil penelitian ini sejalan dengan penelitian yang dilakukan oleh Dwi Purwati (2018) yang menyatakan bahwa tidak adanya pengaruh pelatihan K3. Dari hasil wawancara telah diberikan pelatihan terkait dengan K3 berupa orientasi oleh divisi K3 perusahaan mengenai pengertian dan tujuan K3, identifikasi faktor penyebab kecelakaan kerja, dan penggunaan alat pelindung diri saat bekerja hingga mereka paham sebelum melaksanakan pekerjaan, dari hasil kuesioner menunjukkan buruh secara tidak merata menadapatkan 
pelatihan khusus dikarenakan hanya beberapa orang yang ditunjuk langsung oleh perusahaan mengikuti pelatihan khusus dan menurut asumsi mereka dirasa masih kurang pengetahuanya lewat kegiatan pelatihan $\mathrm{K} 3$ tentang peraturan atau program K3 dimana materi yang disajikan tidak sesuai dengan resiko ditempat mereka bekerja.

Selain itu pelatihan K3 yang diupayakan oleh perusahaan untuk mengembangkan sumber daya manusia dalam bidang K3 baik secara internal yang dilakukan oleh perusahaan sendiri maupun secara eksternal dari CV. Budi Karya dan PT. Bauer Pratama Indonesia sebagai lembaga yang bekerja sama dengan perusahaan.

\section{Hubungan Pemeriksaan Kesehatan Berkala dengan Produktivitas Kerja}

Berdasarkan tabel 5.11 hasil uji Chi Square yang telah dilakukan di PT. PP (Persero) Tbk Proyek Makassar New Port diperoleh hasil $p=0,002<\alpha=0,05$ dengan keterangan $\mathrm{Ha}$ diterima dan $\mathrm{HO}$ ditolak bahwa ada hubungan yang signifikan antara pemeriksaan kesehatan berkala.

Hasil penelitian ini sejalan dengan penelitian yang dilakukan Renaldo (2018) yang menyatakan terdapat hubungan antara pemeriksaan kesehatan terdapat produktivitas kerja. Variabel pemeriksaan kesehatan berkala akan dapat meningkatkan produktivitas kerja buruh sebesar 0,001 yang dapat diartikan bahwa sangat besar kemungkinan apabila setiap buruh secara rutin melaksanakan pemeriksaan kesehatan dapat meningkatkan produktivitas dalam bekerja. Pemeriksaan kesehatan berkala yang dilakukan perusahaan PT. PP (Persero) Tbk berupa pemeriksaan jasmani pra penempatan kepada tiap tenaga kerja baru, pemeriksaan jasmani secara berkala bagi setiap tenaga kerja dalam hal ini pemeriksaan gula darah, asam urat dan kolesterol, serta fasilitas kesehatan berupa pemeriksaan tekanan darah yang dilakukan klinik milik perusahaan, serta tersedianya tenaga perawat yang diperuntukkan bagi setiap buruh yang mengalami keluhan.

Hal ini tertuang dalam Peraturan Menteri Kesehatan Republik Indonesia Nomor 52 Tahun 2018 Tentang Keselamatan dan Kesehatan Kerja di Fasilitas Pelayanan Kesehatan. Bahwa pemeriksaan kesehatan bagi sumber daya manusia perlu dilakukan minimal satu tahun sekali, hal ini perlu dilakukan guna untuk mengetahui kondisi kesehatan buruh untuk memantau kesehatan/penyakit yang mungkin timbul oleh karena akibat dari pekerjaan yang dilakukan. Pemeriksaan kesehatan berkala ini menjadi sangat penting bagi sebuah instantasi sebesar PT. PP (Persero) Tbk dikarenakan dapat mempengaruhi kinerja buruh apabila produktivitas rendah bahkan menurun karena gangguan kesehatan. Semakin rutin seorang buruh memeriksakan kesehatannya maka kemungkinan peningkatan produktivitas kerja itu ada.

\section{Hubungan Penggunaan APD dengan Produktivitas Kerja}

Hasil wawancara kuesioner dengan para pekerja, bahwa besarnya manfaat dari penggunaan APD ini pada saat bekerja tidak menjamin semua pekerja akann memakainya karena ternyata masih banyak juga pekerja yang tidak menggunakannya. Keefektifan penggunaan APD adalah tergantung dari pekerjanya sendiri. Banyak faktor yang mempengaruhi perilaku pekerja sehingga tidak menggunakan APD yang menyebabkan ketidaknyamanan dan kurang enak yang berakibat penurunan performa kerja selain itu juga dapat menimbulkan bahaya kesehatan dan keselamatan kerja yang baru.

Dari tabel 5.12 hasil penelitian dengan uji Chi Square di PT. PP (Persero) Proyek Makassar New Port diperoleh hasil $p=0,023$ $<\alpha=0,05$ dengan keterangan $\mathrm{Ha}$ diterima dan $\mathrm{HO}$ ditolak karena terdapat hubungan yang signifikan antara penggunaan APD dengan produktivitas kerja buruh saat bekerja.

Hasil penelitian yang dilakukan oleh Renaldo (2018) yang menyatakan adanya hubungan antara penggunaan APD dengan produktivitas kerja. Penelitian ini sejalan dengan kelengkapan dan penggunaan alat pelindung diri (APD) merupakan salah satu elemen yang patut diperhatikan oleh perusahaan agar dapat memperkecil resiko terjadinya kecelakaan kerja atau penyakit akibat kerja yang dapat mempengaruhi produktivitas kerja buruh menurun. Dan PT. PP (Persero) Tbk telah mengantisipasi hal itu dengan menyediakan kelengkapan alat pelindung diri.

$\mathrm{Hal}$ ini menunjukkan bahwa pelaksanaan program keselamatan dan kesehatan kerja di PT. PP (Persero) Tbk terhitung rendah, hal ini membuhktikan bahwa buruh merasa tidak nyaman pada 
Jurnal Sulolipu : Media Komunikasi Sivitas Akademika dan Masyarakat

Vol. 21 No.2 2021

e-issn : 2622-6960, p-issn : 0854-624X

saat menggunakan alat pelindung diri berupa helm, sarung tangan, serta sepatu boots yang disediakan perusahaan sehingga mempengaruhi rendahnya produktivitas buruh selama bekerja. Untuk itu perusahaan bertanggung jawab penuh untuk meningkatkan fasilitas dalam hal ini, helm yang diperuntukkan sesuai dengan risiko pekerjaan yang ditanggung oleh buruh, sarung tangan, sepatu boots yang sebaiknya diganti apabila sudah kusam dan rusak kepada setiap buruh agar memberikan motivasi agar terus semangat dalam bekerja untuk meningkatkan produktivitas kerja.

\section{KESIMPULAN}

Kesimpulan penelitian ini yaitu terdapat hubungan antara pemeriksaan kesehatan berkala dan pengunaan APD dengan produktivitas kerja pada buruh di PT. PP (Persero) Tbk Proyek Makassar New Port. Sedangkan penyuluhan dan pelatihan K3 tidak berhubungan dengan produktivitas kerja pada buruh di PT. PP (Persero) Tbk Proyek Makassar New Port.

\section{SARAN}

Diharapkan kepada perusahaan harus memberikan efek jera dengan memberikan sanksi berupa pemotongan gaji agar buruh lebih taat memakai APD selama bekerja. Kepada petugas klinik agar memberikan jadwal kepada buruh untuk melakukan pemeriksaan kesehatan mengingat jarak antara klinik dan proyek jauh.

\section{DAFTAR PUSTAKA}

Ani Asriani Basri. 2014. Hubungan Pelaksanaan Program Kesehatan dan Keselamatan Dengan Produktivitas Kerja Karyawan Bagian Packer Di PT Semen Bosowa Maros. http://reposotori.uinalauddin.ac.id/

Arlin Riantiwi. 2012. Hubungan Pelaksanaan Program K3 Dengan Produktivitas Kerja Karyawan Pada Divisi Operasional PT. Surveyor Indonesia. http://lib.ui.ac.id/

Delfani Gemely. 2018. Implementasi Sistem Manajemen Keselamatan dan Kesehatan Kerja di PT. Pelindo IV (Persero) Terminal Petikemas Makassar Tahun 2018. http://digilib.unhas.ac.id/

Dwi Purwati, 2019. Hubungan Penerapan Keselamatan Kerja Dengan Risiko Kecelakaan Pada Karyawan di Bagian Produksi PT. Semen Tonasa Kabupaten Pangkep.

Kadir, A. R. 2018. Formulasi Strategi Makassar New Port dan Pelabuhan Bitung Sebagai International Hub Port. Hasanuddin Journal of Applied Business and Entrepreneurship. Vol, 1. No. 4, 10-12. (Dlakses Pada Tanggal 26 Desember 2020)

Lalu Muhammad Saleh, 2018. Keselamatan dan Kesehatan Kerja Kelautan. Yogyakarta; Penerbit CV BUDI UTAMA. (Online) Diakses pada tanggal 31 Desember 2020.

Republik Indonesia. 2019. Peraturan Menteri Kesehatan Republik Indonesia Nomor. 88 Tahun 2019

Tentang Kesehatan Kerja. 
Jurnal Sulolipu : Media Komunikasi Sivitas Akademika dan Masyarakat

Vol. 21 No.2 2021

e-issn : 2622-6960, p-issn : 0854-624X

\section{LAMPIRAN}

Tabel 1

Hubungan Penyuluhan K3 Dengan Produktivitas Kerja Pada Buruh di PT. PP (Persero) Tbk Tahun 2021

\begin{tabular}{|c|c|c|c|c|c|c|c|}
\hline \multirow{3}{*}{ Penyuluhan K3 } & \multicolumn{4}{|c|}{ Produktivitas Kerja } & \multirow{3}{*}{ Total } & \multirow{3}{*}{$\%$} & \multirow{3}{*}{ Uji Statistik } \\
\hline & \multicolumn{2}{|c|}{ Tinggi } & \multicolumn{2}{|c|}{ Rendah } & & & \\
\hline & $\mathrm{N}$ & $\%$ & $\mathrm{~N}$ & $\%$ & & & \\
\hline Mengikuti & 11 & 11 & 86 & 89 & 97 & 100 & \\
\hline Tidak mengikuti & 11 & 20 & 45 & 80 & 56 & 100 & $x^{2}=1,988$ \\
\hline
\end{tabular}

\section{Sumber: Data Primer 2021}

Tabel 2

Hubungan Pelatihan K3 Dengan Produktivitas Kerja Pada Buruh di PT. PP (Persero) Tbk Tahun 2021

\begin{tabular}{|c|c|c|c|c|c|c|c|}
\hline \multirow{3}{*}{ Pelatihan K3 } & \multicolumn{4}{|c|}{ Produktivitas Kerja } & \multirow{3}{*}{ Total } & \multirow{3}{*}{$\%$} & \multirow{3}{*}{ Uji Statistik } \\
\hline & \multicolumn{2}{|c|}{ Tinggi } & \multicolumn{2}{|c|}{ Rendah } & & & \\
\hline & $\mathrm{N}$ & $\%$ & $\mathrm{~N}$ & $\%$ & & & \\
\hline Mengikuti & 4 & 13 & 28 & 86 & 32 & 100 & \\
\hline Tidak mengikuti & 18 & 15 & 103 & 85 & 121 & 100 & $x^{2}=0,003$ \\
\hline
\end{tabular}

\section{Sumber: Data Primer 2021}

Tabel 3

Hubungan Pemeriksaan Kesehatan Berkala Dengan Produktivitas Kerja Pada Buruh di PT. PP (Persero) Tbk Tahun 2021

\begin{tabular}{|c|c|c|c|c|c|c|c|}
\hline \multirow{3}{*}{$\begin{array}{l}\text { Pemeriksaan } \\
\text { Kesehatan } \\
\text { Berkala }\end{array}$} & \multicolumn{4}{|c|}{ Produktivitas Kerja } & \multirow{3}{*}{ Total } & \multirow{3}{*}{$\%$} & \multirow{3}{*}{ Uji Statistik } \\
\hline & \multicolumn{2}{|c|}{ Tinggi } & \multicolumn{2}{|c|}{ Rendah } & & & \\
\hline & $\mathrm{N}$ & $\%$ & $\mathrm{~N}$ & $\%$ & & & \\
\hline Melaksanakan & 18 & 24 & 58 & 76 & 76 & 100 & \\
\hline $\begin{array}{c}\text { Tidak } \\
\text { melaksanakan }\end{array}$ & 4 & 5 & 73 & 95 & 77 & 100 & $x^{2}=9,172$ \\
\hline
\end{tabular}

\section{Sumber: Data Primer 2021}

Tabel 4

Hubungan Penggunaan APD Dengan Produktivitas Kerja Pada Buruh di PT. PP (Persero) Tbk Tahun 2021

\begin{tabular}{|c|c|c|c|c|c|c|c|}
\hline \multirow{3}{*}{$\begin{array}{l}\text { Pemeriksaan } \\
\text { Kesehatan } \\
\text { Berkala }\end{array}$} & \multicolumn{4}{|c|}{ Produktivitas Kerja } & \multirow{3}{*}{ Total } & \multirow{3}{*}{$\%$} & \multirow{3}{*}{ Uji Statistik } \\
\hline & \multicolumn{2}{|c|}{ Tinggi } & \multicolumn{2}{|c|}{ Rendah } & & & \\
\hline & $\mathrm{N}$ & $\%$ & $\mathrm{~N}$ & $\%$ & & & \\
\hline Menggunakan & 12 & 24 & 39 & 76 & 51 & 100 & \\
\hline $\begin{array}{c}\text { Tidak } \\
\text { menggunakan }\end{array}$ & 10 & 10 & 92 & 90 & 102 & 100 & $x^{2}=5,203$ \\
\hline
\end{tabular}

